\title{
Concept Development of Public Art and Its Reflection
}

\author{
Le Liu \\ International School \\ Huanghe Science and Technology College \\ Zhengzhou, China 450046 \\ E-mail: 604701937@qq.com
}

\begin{abstract}
As a newly forwarded concept under development, public concept has aroused wide attention in recent years, covering a wide range of fields such as visual design, psychology, history and ecology etc. because it is an important form for communication in public space between artworks and the public, and it covers multi art fields such music, drawing, architectural design, landscape design, performance music and so on in form. There hasn't been a unified definition about it due to its diversified involvement of form and field, and the concept of it in under development at the present times. This paper mainly describes the concept and practice of public art and the current research and development condition in home and abroad, as well as some viewpoints of the author while learning public are ideas and studying creation methods of public art, among which, the attention is attached to key words of public art characteristics: "Public Space, Public Involvement, and Benefit to the Public", and the key words of public artist characteristics: "Emotional feelings of artistic beauty, rational thinking of design and social accountability".
\end{abstract}

Keywords-public art; development; research; positioning; recognition

\section{INTRODUCTION}

The concept of "Public Art" is proposed before long, but it is quite a long time since the ancient time without interruption. Different dynasty, different people, different religion and cultural factors all lead to generation of different concept and artwork. Yet one thing that never changed is the perception and desire of the public for beauty, the desire for free communication in public space. And the presentation of public art concept in recent years has settled most of those problems. It has reflected the awareness of freedom and spirit of democracy; meanwhile, it has balanced the incongruity between material life improvement and aesthetics spirit. He tries to influence the environment with a finished touch using the minority to bring along the majority, thus to influence the public's aesthetic and spirit experience, realizing the communication between each free individual, and to provide a positive effect in objective material world and the humanity mental world.

\section{CURRENT DEVELOPMENT, RESEARCH AND POSITIONING OF PUBLIC ART IN THE WORLD}

To figure out the concept of public art, the concept of public domain theory shall be explained clearly first of all. In the region where German is spoken, Schumpeter (1918) and Bruner (1943) have made research on the issues in "Public Domain". And in the region where English is spoken, Dewey (1923) and Arendt, a German-Jewish female scholar, have discussed relevant issues in public art from the aspect of art philosophy respectively.

Hannah Arendt, a German-American political philosopher, is a pioneer in this field. Arendt holds the opinion that the so called public domain is a place to realized action, a political space where people can communicate and participate in action freely and equally. Action refers to the direct contact between people without any tool, which is a product at a higher stage in the development process of human.

German philosopher Jürgen Habermas carried forward Arendt's viewpoint about art, namely, takes the public domain as the main site for collecting and comparing the ideas. And he has proposed concepts of various public domain, such as "Representative Public Domain", "Literature Public Domain" "Political Public Domain" and so on, thus makes the theory of public domain developed further.

"Public Art" has aroused the attention along with the development and change in political, economy and urban construction in European and American countries since 1960s. The concept of public art is presented in specific social and cultural background, and is gradually recognized with mature development.

The reason why this concept is generated, firstly, is that the separation of technology and art in industrial age leads the splitting of history and reality. And the significant improvement in material life enables people to pay more attention to enrich spiritual world.

Secondly, since the Enlightenment Movement in the 18th century till now, western democratic society is perfected gradually, and the huge development of democratic system and democratic concept has been accepted and recognized by 
the public deeply, which has promoted the development of public utilities and influenced urban construction and cultural art field.

Thirdly, the environment ravaged by the World War II makes everything need to be rebuilt, rendering the development of public art environment to be a necessity.

Fourth, along with the economic accumulation and political concept changes, more attention is attached to the localized art and humanistic environment in modern construction. Western countries have formulated a number of system policy and funding support.

Fifth, the art forms form different trends render the public culture an unprecedented development, which has aroused the public' rethink about the concept of authority and rights, making the expansion of public art from merely the aesthetic significance to the fields of sociology and culturology, and meanwhile, the humanistic progress in sociology and philosophical has also generated influence on the public art.

\section{BACKGROUND OF PUBLIC ART EMERGENCE AND DEVELOPMENT IN CHINA}

Public art is generated when the society develops to a certain extent. Western countries have experienced those changes in public art early, while China also has developed a lot in the process of democratization of social public utilities and cultural art development. Therefore, we have a different social and history background from western countries, the development of public art will be an absolute trend of social art development.

Under China's national condition, the scholars in our country have no unified opinion about how to define the "Public Art" as a new thing, how to divide pattern of manifestation, how to determine the right of speech, and how to really become "Public" and "Art". The experts and scholars in our country have put forward the concept of public art in late 1980s. In the development of more than 20 years, various scholars and artists have defined and described the concept of public are differently, with some divide it from the broad and narrow sense, some evaluate it from the perspective of environmental open space, and some other define it from the aspect of form and publicity of the public art. Here I give several artists' viewpoints with real significance in the international view and in line with modern ecological view:

First, Bao Lin, professor of Academy of Arts \& Design, Tsinghua University, holds the opinion that public art is neither a definite style or school, nor a certain single form. No matter the art is expressed through which material carrier or transmitted in which language, first of all, it is a social and cultural value orientation which in particularly refers to the art. This value orientation takes serving the public using art as a precondition, enabling the artist to create art works that integrate to specific public environment in accordance with certain participation procedure, and thus to enhance, cultivate or enrich the public's visual aesthetic experience."
The Public Art Program passed in 1994 - the work of Wrapped Reichstag by Christo \& Jeanne-Claude, pioneers in public art field, rebuilt a building using Canvas packages with an area of $110,000 \mathrm{~m} 2$ and weighing 90 tons, setting up a commemorative significance of architecture in people's mind, and making Germans in East and West Berlin to reestablish an awareness of peace and friendship. This is not to build a new art museum or memorial hall, but to make people to connect with others or an event through a public aesthetics event. This is an action but not a kind of symbol.

Second, Professor Xiao Jingcong of The Hong Kong Polytechnic University has indicated that "Public art need not to be described using the method of "hardware", and it may not be the artwork placed at the street of the city, but it can be displayed or expressed using other ways. Public art may not be something created by the artist, but it can be a city narrative style expressed by cooperation with the public, or the expression by the public against some public issues, a state of citizen. The so called public art may a set of strategy, aiming to connect the identity and capacity of "the public", to perfect some established and fossilized public privilege framework and operation policy."

In January 1995, violent earthquake hit Kobe Japan. Art creation has been involved in the various reconstruction plans for rebuilding Hyogo Province. One of which is to design a gate for the architecture, another is an outdoor perfection plan. Tian Fu Ritsuko has conducted a project named Happy Farmland with many Regulations on the space between buildings. The artist wishes to arouse people's memory about the glorious traditional willingness of farming, meanwhile to satisfy people's "desire of planting", thus strengthened the unfamiliar neighborhood relationship as it is a creation in community. This is the first farmland community operated and managed by their own in Japanese Public House. Happy Farmland with many Regulations is an artwork, and can be seen as a war of local community against modern city's internationalization and standardization, and resist against the dehumanization by the state using centralization after the earthquake.

Third, Artist Wang Luyan holds the opinion that "The relationship between public art and the public is a relation of "to force and to be forced", and it is a significant difference between public art and non-public art." He attaches the relationship of subjective-objective and active-passive between art and the audience, indicating that, actually, some so called public sculptures on the street have come into our view by an attitude of "aggression". And those works that cannot bring about sense of beauty and spiritual enhancement shall not appear directly without reason.

It is reported by the BBC that, upon the compliant by relevant authority of Egypt to the United Nations that there is a counterfeit of Sphinx in Hebei Province, this statue will be removed, arousing enormous response from the society. Hence, the "Eiffel Tower", "Court of Versailles" etc. in suburban of Hangzhou, and the sculptures of David, and the four former US presidents in Chongqing are revealed. We don't make any comments on those works that they are good or bad. They are the cultural legacy generated from 
thousands of years of foreign countries' history, how can they come to China in a sudden? And what relation do they have with current China's ecology and its future? I wonder how the public will feel when those scenes come into their view by force. It is just a ridiculous thing.

We can get a conclusion roughly that different people and different artists pay attention to it from a different starting point. But if we take off its cover, we can find out that their concept of internal structure is consistent, and this is the public issue of public art. Yet its publicity shall have a dynamic background, and it is a concept of "publicity" with different periods of the social development, different regions, different culture, different race etc. as its background.

Currently, China's public art may grow up rapidly in practice under China's specific national condition taking that of western countries as reference. In such a "blending" age, we not only have the public art of foreign excellent humanistic ideas, but also have learned some surface knowledge about it. But I believe that along with China continuously developing into a more country, our public cultural undertakings will move toward mature gradually. In this stage, the public artists shall create more and more good works, enabling the public to experience and participate in the public art practice in person, thus the positive development ecology of public art formed.

\section{RECOGNition OF Public ART}

There are various opinions about positioning the concept of public art currently. On the basis of social development, continuous perfection of the political system and enhancement of the public's aesthetic cognition, the concept of public art will develop continuously. It is difficult to summarize those academic viewpoints, but we can conclude and deepen some of our own viewpoints based on the research by those experts and scholars.

In my opinion, if we see from current condition, public art is not a new subject of aesthetics, but a new development and surpass of the aesthetics subject from ancient times in combination with science and social ecology in modern times. Actually it is aesthetic view and art form of modern ecological ontology including ecological latitude. It takes the eco-aesthetics relationship between human and nature as a starting point, including the eco-aesthetics relationship between human and nature, society as well as the human themselves, with the purpose to realize Heidegger's "Poetic Dwelling". It is an art concept with multi forms, and it is a carrier for a city or country's cultural inheritance with characteristics of non-independence of cross-disciplinary. Take such public space as specific garden, landscape planning, architectural design and public facilities or even a certain part of the public's daily life as a carrier, to make the art combine with historical context and public values in different expression forms through public participation. It is an art concept derived from life but higher than life, enhancing the public's aesthetic experience continuously, thus to influence the sustainable development of spiritual and civilization construction of a city, and an ecological and sustainable humanity concept.
Although there hasn't been a unified definition about the concept of public art in the world, if we have to make clear the concept of it, I try to put forward the following conclusion based on summary of the public artist' concept with different starting point and different purpose:

The basic characteristic of public art is that it is a creative artwork taking the objective existing things as its main body, and has beneficial influence on social and humanistic ecology. Public art is different from personal art creation, which can take the cognition and feelings to the "world" by themselves as a center to create their own spiritual world artistically, and the public is in a state of being accepted. While the publicity of public art has determined its starting point and ultimate objective is to make the public gain benefits: facilitate the artistry of public space, increase free communication for the public in this space, and enhance the public's aesthetic appreciation; strengthen the coordination and sustainability between the whole humanity and natural ecology. Therefore, the key words of public art characteristics are: Public Space, Public Involvement, and Benefit to the Public.

First, public art can be temporary or perpetual in terms of time attribute;

Second, it is an open and non-personal space in terms of space attribute not only from the perspective physical conception, but it includes public sharing from the perspective of sociology and politics, and the space with democratic participation from the perspective of spiritual connotation. Public space is where anyone has access to without limitation to economic and social condition (even though actual condition may not be so), for example, people can enter it without payment or ticket, or entrants may not be discriminated due to their backgrounds. Physical space is the space we can cognize and feel, while cyber space is a public non-physical space.

Third, in terms of object attribute, prior to, during and after the creation, public figures may appear and participate in.

Fourth, in terms of event attribute, there must have activity process with reflection and involvement of public opinion, and its results and influence.

Influence of public art: it core is for the public's benefits, and to facilitate the artistry of public space, increase free communication of the public in this space, and enhance the public's aesthetic appreciation on the basis of satisfaction of public space's function; strengthen the coordination and sustainability between the whole humanity and natural ecology.

There may be various limitations in the process of public art creation, for example, the public's aesthetic appreciation level and receptivity, ethnic and religious, geographical and cultural factors in different regions, and the one that plays a vital role is the coordination between individual aesthetic and public art creation of the public artist who coordinates each party's "benefits". As a result, for an excellent public artist, the work he presents shall not only be a creation with personal art cognition and understanding, but also a public 
art work "with good tastes and sense of beauty, coordination of various factors or contradictions (e.g. the contradiction between artistry and the public's aesthetic appreciation and receptivity), settlement of part of current realistic problems with the public as the core" after taking a full consideration of various factors and making a coordination of all the above mentioned elements. Hence, the key words of public artist are: "Emotional feelings of artistic beauty, rational thinking of design and social accountability".

\section{REFERENCES}

[1] Ding Ning. Extensive Thought -- Understanding Philosophy of Art History, Beijing: Sanlian Publishing Press, 1997.

[2] Hans Belting, et al. End of Art History? Beijing: Renmin University of China Press, 2004. 